\title{
Integrated Probabilistic Surface Roughness Assessment for Various Processing Methods
}

\author{
Igor Bobrovskij ${ }^{1,2,3, *}$, Petr Zibrov², Aleksey Luk’yanov³ ${ }^{3}$ Olesja Levitskih ${ }^{3}$ \\ ${ }^{1}$ Almetyevsk State Oil Institute, RU-423450, Tatarstan, Almetyevsk, Russian Federation \\ ${ }^{2}$ Togliatti State University, RU-445020 Togliatti, Russian Federation \\ ${ }^{3}$ Samara Scientific Center of Russian Academy of Science, RU-443001, Samara, Russian Federation
}

\begin{abstract}
The surface texture characteristics are specified by international standards, which include dozens of parameters, basically geometrical. The probability of filling the rough surface layer with a material from the reference line and through the layer thickness is proposed as a quantitative roughness assessment. It takes account of geometrical parameters, shape, height and frequency of surface irregularities. An example is given of studying a surface with processing defects, and a comparative analysis of surface treatment methods is presented. The calculation results are summarized in a table of probabilistic characteristics of surfaces for various processing methods.
\end{abstract}

\section{Introduction}

The probabilistic parameters of presence of a material within a section of the surface layer and through the entire layer thickness are evaluated using the computational and graphical method for studying the rough surface profilograms obtained from various processing methods.

The probability of filling density $P\left(S_{\alpha i}\right)$ in $i$-th section relative to the surface reference line is calculated as [13]:

$$
P\left(S_{\alpha i}\right)=\frac{M_{i}}{l},
$$

where $M_{i}=\sum_{j=1}^{m_{i}} M_{i j}, l$ - profilogram base length. $M_{i j}$ - width of the $j$-th peak in the $i$-th section;

$m_{i}$ - the number of peaks in the specified section;

$l$ and $M_{i j}$ are measured in the same linear units shown on the profilogram (Fig.1);

$0 \leq P\left(S_{a i}\right) \leq 1$ - the probability of filling density in the $i$ th section, a dimensionless value.

It should be noted that in the Abbott curve definition there is an assumption about its correspondence to the probability density, which is not correct, since the probability density characterizes the maximum of the probability change rate at the point of the interval. In the present case the amount of the material in the section changes and the formula above corresponds to the graphical probability definition of the considered event.

$P\left(S_{\alpha}\right)$ curves constructed for real profilograms are close to parabola form. Their equations, which best fit the obtained statistical data, can be written as:

$$
s=(1-\alpha)(1-\beta \alpha)
$$

The dimensionless coefficient $\beta$ is obtained from the statistical data $\mathrm{P}(\mathrm{S} \alpha \mathrm{i})$ and $\alpha \mathrm{i}$ using the least squares method:

$$
\beta=-\frac{\sum_{i=1}^{n}\left[P\left(S_{\alpha i}\right)-\left(1-\alpha_{i}\right)\right]\left(1-\alpha_{i}\right) \alpha_{i}}{\sum_{i=1}^{n}\left(1-\alpha_{i}\right)^{2} \alpha_{i}^{2}}=-\frac{\xi}{\eta}
$$

Here $\quad \xi=\sum_{\mathrm{i}=1}^{\mathrm{n}} \xi_{\mathrm{i}}, \quad \eta=\sum_{\mathrm{i}=1}^{\mathrm{n}} \eta_{\mathrm{i}}, \quad \xi_{\mathrm{i}}=\left[\mathrm{P}\left(\mathrm{S}_{\text {ai }}\right)-(1-\right.$ $\left.\left.\alpha_{i}\right)\right]\left(1-\alpha_{i}\right) \alpha_{i}, \eta_{i}=\left(1-\alpha_{i}\right)^{2} \alpha_{i}^{2}, \beta$ is taken with its own sign.

The probability of a material within a section of the surface layer and through the entire layer thickness is found from the following formula [4-8]:

$$
P\left(V_{\alpha i}\right)=1+\frac{1+\beta}{2} \alpha_{i}+\frac{\beta}{3} \alpha_{i}^{2}
$$

For a smooth curve $P\left(S_{i}\right)$ along with the indicated relation, the graphical integration by the chord method can be used:

$$
P\left(V_{\alpha i}\right)=\frac{1}{k}\left[\frac{P\left(S_{0}\right)+P\left(S_{k}\right)}{2}+\sum_{j=1}^{k-1} P\left(S_{j}\right)\right], i=k=1,2, \ldots, n,
$$

where $n$ - the number of sections of the rough layer along the $O Z$ axis.

\section{Results and discussion}

In accordance with the formula $P\left(V_{\alpha=1}\right)$, which gives value of the probability of the through-thickness filling the rough layer with a material, the Simpson's formula is suitable, adapted for the present case.

$$
\begin{gathered}
P\left(V_{\alpha=1}\right)_{\operatorname{sim}}= \\
\frac{1}{6 m}\left[1+2 \sum_{i=1}^{m-1} P\left(S_{\alpha 2 i}\right)+4 \sum_{i=1}^{m} P\left(S_{\alpha 2 i-1}\right)\right] .
\end{gathered}
$$


Here $\mathrm{m}$ is integer and $n=2 m, n$ - number of sections across the rough layer thickness.

The relative difference in results found by Simpson's formula and the approximating parabola satisfying the least squares method will be:

$$
\delta=\left|1-\frac{P\left(V_{\alpha-1}\right)_{\operatorname{Sim}}}{P\left(V_{\alpha-1}\right)}\right| \cdot 100 \%
$$

It quantitatively characterizes the difference between the found characteristics.

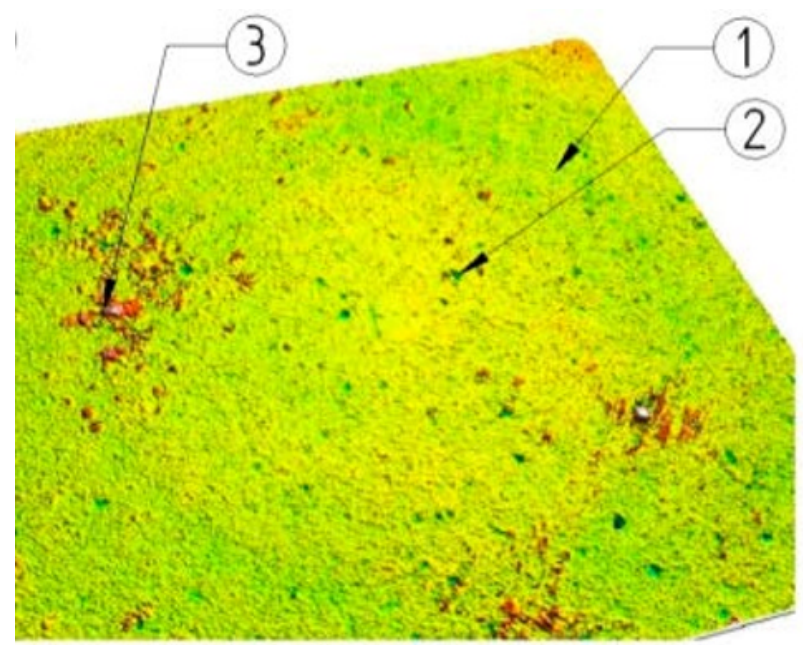

Fig.1. Photo of a processed surface with defects.

Length $=319.375 \mu \mathrm{m} \mathrm{Pt}=146.675 \mathrm{~nm} \mathrm{Scale}=200.000 \mathrm{~nm}$

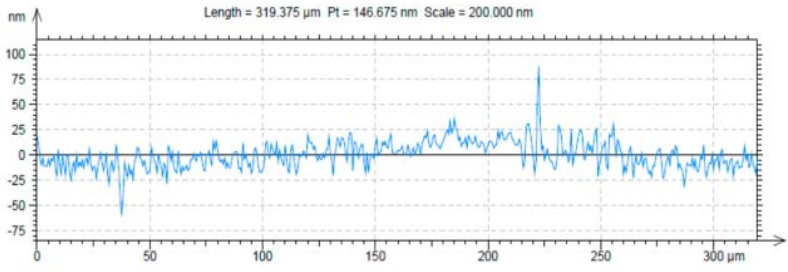

Fig. 2. Example of an imperfect surface profilogram.

As an example, the studies of the surface shown in Figure 1 [9-11] are presented; its profilogram is given in Figure 2. The defects in areas 2 and 3 are noted due to: surface pores in area 2 and material adhered to the ball during rolling is redistributed to the area 3.

The original profilogram is divided into three sections. A computational and graphic study of the probability of the material presence in the surface irregularities is conducted using complex parameters according to the dependences presented above, and obtained results are compared.

The use of dimensionless characteristics makes it possible to choose the base length and the profilogram width for various sizes of a rough layer, compare them in relative units and identify the features of each section considering the trends in microroughness.

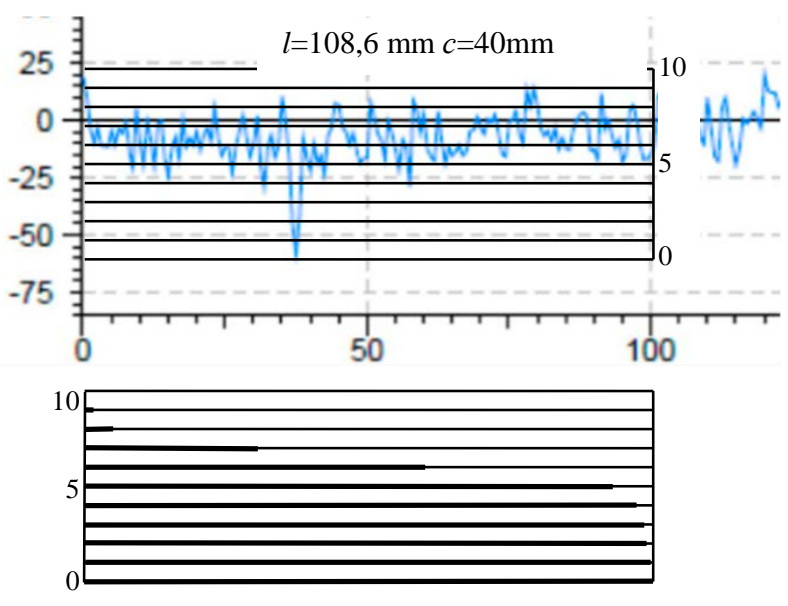

Fig. 3. Profilogram and diagram of filling the rough layer with a material along the $0-100$ section of the profilogram depicted on fig. 2.

Table 1. Results of probabilistic parameters calculation along the length $0-100 \mathrm{~mm}$ of the profilogram.

\begin{tabular}{|l|c|c|c|c|c|c|}
\hline$\alpha_{i}$ & 0 & 0,1 & 0,2 & 0,3 & 0,4 & 0,5 \\
\hline$P\left(S_{\alpha i}\right)$ & 1 & 0,9917 & 0,9880 & 0,9816 & 0,9742 & 0,9227 \\
\hline$\xi_{\mathrm{i}}$ & 0 & 0,0083 & 0,0301 & 0,0591 & 0,0898 & 0,1057 \\
\hline$P\left(V_{\alpha i}\right)_{\mathrm{Tp}}$ & 1 & 0,9959 & 0,9929 & 0,9902 & 0,9871 & 0,9794 \\
\hline$P\left(V_{\alpha i}\right)$ & 1 & 0,9934 & 0,9806 & 0,9616 & 0,9364 & 0,9050 \\
\hline $\mathrm{s}_{\mathrm{i}}$ & 1 & 0,9837 & 0,9488 & 0,8953 & 0,8232 & 0,7325 \\
\hline
\end{tabular}

Table 1. Continuation

\begin{tabular}{|c|c|c|c|c|}
\hline 0,6 & 0,7 & 0,8 & 0,9 & 1,0 \\
\hline 0,6261 & 0,2753 & 0,0497 & 0,0076 & 0 \\
\hline 0,0545 & $-0,0052$ & $-0,0240$ & $-0,0083$ & 0 \\
\hline 0,9453 & 0,8747 & 0,7857 & 0,7016 & 0,6314 \\
\hline 0,8674 & 0,8236 & 0,7736 & 0,7174 & 0,6551 \\
\hline 0,6232 & 0,4953 & 0,3488 & 0,1837 & 0 \\
\hline
\end{tabular}

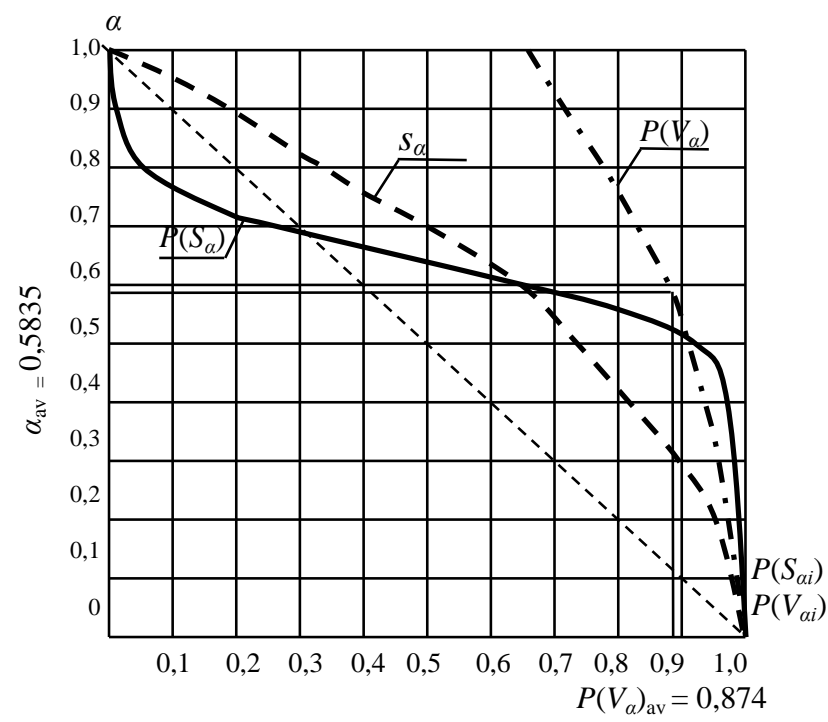

Fig. 4. $\mathrm{P}(\mathrm{S} \alpha), \mathrm{P}(\mathrm{V} \alpha)$ and $\mathrm{s}(\alpha)$ curves constructed for the profilogram and diagram depicted on fig. 3 (first section of the profilogram on fig. 2). 
Quantitative values in the calculation formulas for the first section on fig. 2 .

$$
\begin{gathered}
\xi=0,31, \eta=0,3333, \beta=-0,9301 ; \\
P\left(V_{\alpha i}\right)=1-\left(0,03495+0,3100 \alpha_{i}\right) \alpha_{i} ; \\
s_{i}=\left(1-\alpha_{i}\right)\left(1+0,9301 \alpha_{i}\right) \\
\delta=1-\frac{0,6314}{0,6551}=0,036 \text { or } 3,6 \% ;
\end{gathered}
$$

$P\left(V_{\alpha}\right)_{a v}=0,8740 ; \alpha_{a v}=0,5835 ; P\left(V_{\text {тр }}\right)_{a v}=0,8986$.

$\mathrm{l}=106,5 \mathrm{~mm} \mathrm{c}=30 \mathrm{~mm}$

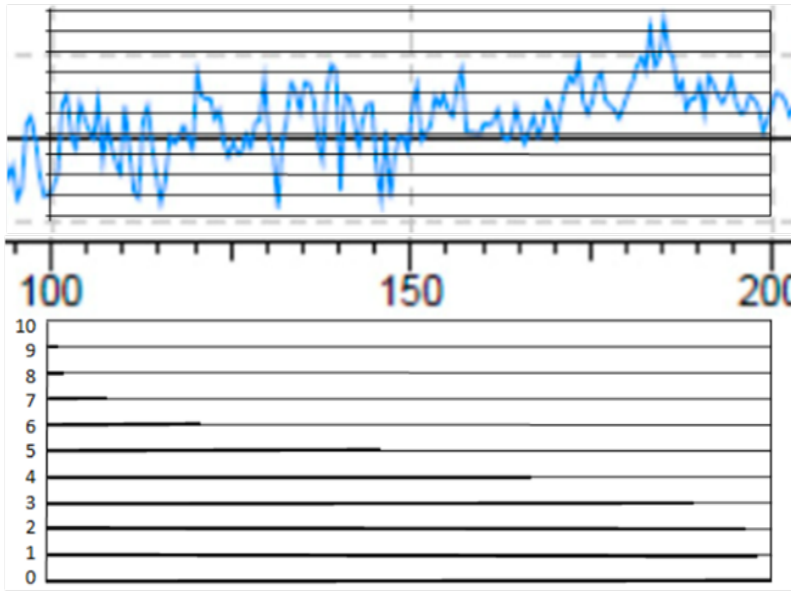

Fig. 5. Profilogram and diagram of filling the rough layer with a material along the 100-200 section of the profilogram depicted on fig. 2.

Table 2. Results of probabilistic parameters calculation along the length $100-200 \mathrm{~mm}$ of the profilogram.

\begin{tabular}{|l|c|c|c|c|c|}
\hline$\alpha_{i}$ & 0 & 0,1 & 0,2 & 0,3 & 0,4 \\
\hline$P\left(S_{\alpha i}\right)$ & 1 & 0,9793 & 0,9606 & 0,8714 & 0,6488 \\
\hline$\xi_{\mathrm{i}}$ & 0 & 0,0071 & 0,0257 & 0,0360 & 0,0117 \\
\hline$P\left(V_{a i}\right)_{\mathrm{Tp}}$ & 1 & 0,9897 & 0,9798 & 0,9585 & 0,9089 \\
\hline$P\left(V_{a i}\right)$ & 1 & 0,9407 & 0,8827 & 0,8260 & 0,7707 \\
\hline $\mathrm{s}_{\mathrm{i}}$ & 1 & 0,8820 & 0,7680 & 0,6580 & 0,5520 \\
\hline
\end{tabular}

Table 2. Continuation

\begin{tabular}{|c|c|c|c|c|c|}
\hline 0,5 & 0,6 & 0,7 & 0,8 & 0,9 & 1,0 \\
\hline 0,4493 & 0,2006 & 0,0676 & 0,0150 & 0,0089 & 0 \\
\hline$-0,0127$ & $-0,0479$ & $-0,0488$ & $-0,0296$ & $-0,0082$ & 0 \\
\hline 0,8370 & 0,7516 & 0,6634 & 0,5856 & 0,5219 & 0,4702 \\
\hline 0,7167 & 0,6640 & 0,6127 & 0,5627 & 0,5140 & 0,4667 \\
\hline 0,4500 & 0,3520 & 0,2580 & 0,1680 & 0,0820 & 0 \\
\hline
\end{tabular}

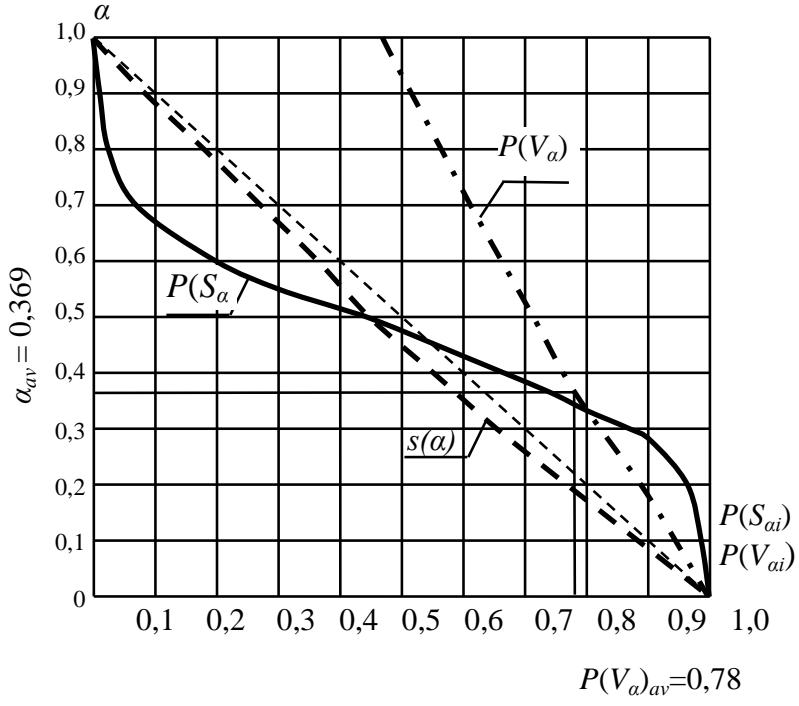

Fig. 6. $\mathrm{P}(\mathrm{S} \alpha), \mathrm{P}(\mathrm{V} \alpha)$ and $\mathrm{s}(\alpha)$ curves constructed for the second section of the profilogram depicted on fig. 2.

Quantitative values in the calculation formulas for the second section on fig. 2 .

$$
\begin{gathered}
\xi=-0,0667 ; \eta=0,3333 ; \beta=0,2001 ; \\
P\left(V_{\alpha i}\right)=1-\left(0,6-0,667 \alpha_{i}\right) \alpha_{i} ; \\
s_{i}=\left(1-\alpha_{i}\right)\left(1-0,2001 \alpha_{i}\right) ; \\
\delta=1-\frac{0,4667}{0,4702}=0,0074 \text { or } 0,74 \% ; \\
P\left(V_{\alpha}\right)_{a v}=0,7878 ; \alpha_{a v}=0,369 ; P\left(V_{\text {тр }}\right)_{a v}=0,7879 .
\end{gathered}
$$
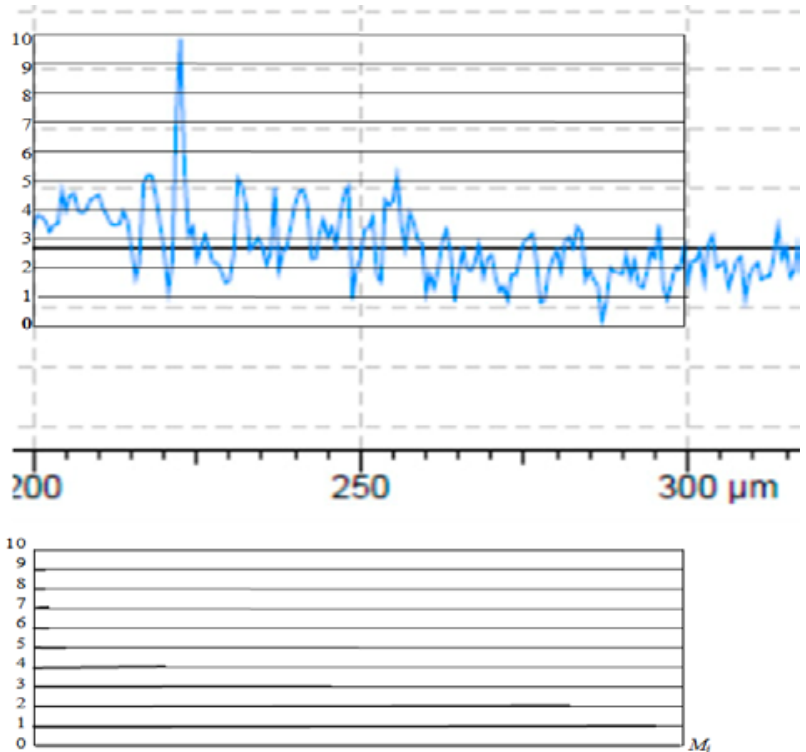

Fig. 7. Profilogram and diagram of filling the rough layer with a material along the 200-300 section of the profilogram depicted on fig. 2. 
Table 3. Results of probabilistic parameters calculation along the third section (200-300 mm).

\begin{tabular}{|l|c|c|c|c|c|}
\hline$\alpha_{i}$ & 0 & 0,1 & 0,2 & 0,3 & 0,4 \\
\hline$P\left(S_{\alpha i}\right)$ & 1 & 0,9713 & 0,7568 & 0,4446 & 0,1676 \\
\hline$\xi_{\mathrm{i}}$ & 0 & 0,0064 & $-0,0069$ & $-0,0536$ & $-0,1038$ \\
\hline$P\left(V_{\alpha i}\right)_{\text {тр }}$ & 1 & 0,9857 & 0,9249 & 0,8168 & 0,6891 \\
\hline$P\left(V_{\alpha i}\right)$ & 1 & 0,8851 & 0,7795 & 0,6831 & 0,5961 \\
\hline $\mathrm{s}_{\mathrm{i}}$ & 1 & 0,7749 & 0,5776 & 0,4080 & 0,2663 \\
\hline
\end{tabular}

Table 3. Continuation

\begin{tabular}{|c|c|c|c|c|c|}
\hline 0,5 & 0,6 & 0,7 & 0,8 & 0,9 & 1,0 \\
\hline 0,0395 & 0,0164 & 0,0160 & 0,0096 & 0,0085 & 0 \\
\hline$-0,1151$ & $-0,0921$ & $-0,0596$ & $-0,0305$ & $-0,0082$ & 0 \\
\hline 0,5720 & 0,4813 & 0,4149 & 0,3645 & 0,3251 & 0,2930 \\
\hline 0,5183 & 0,4497 & 0,3904 & 0,3404 & 0,2997 & 0,2682 \\
\hline 0,1524 & 0,0066 & 0,0008 & $-0,0224$ & $-0,0251$ & 0 \\
\hline
\end{tabular}

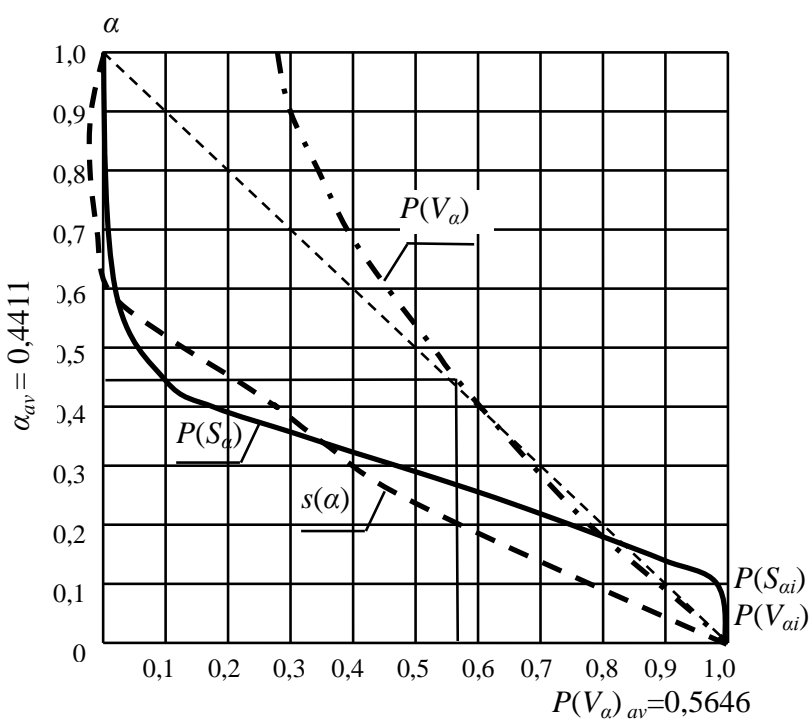

Fig. 8. $P(S \alpha), P(V \alpha)$ and $s(\alpha)$ curves constructed for the third section of the profilogram depicted on fig. 2).

Quantitative values in the calculation formulas for the third section on fig. 2 .

$$
\begin{gathered}
\xi=-0,4634, \eta=0,3333, \beta=1,3903 . \\
P\left(V_{\alpha i}\right)=1-\left(1,1952-0,4634 \alpha_{i}\right) \alpha_{i} ; \\
s_{i}=\left(1-\alpha_{i}\right)\left(1-1,3903 \alpha_{i}\right) ; \\
P\left(V_{\alpha}\right)_{a v}=0,5646, \alpha_{\mathrm{cp}}=0,4411, P\left(V_{\mathrm{тр}}\right)_{a v}=0,6244 . \\
\delta_{1,2}=0,2553 \approx 25,5 \% \\
\delta_{1,2}=0,536 \approx 53,6 \% \\
\delta_{1,2}=0,6231 \approx 62,3 \% .
\end{gathered}
$$

The results of the computational and graphic study show that the probabilities of filling the rough layer with a material have significant difference at each of the three sections, that is from $25.5 \%$ to $62.3 \%$. Such variation indicates the inhomogeneity of the rough layer.

\begin{tabular}{|c|c|c|c|c|c|}
\hline № & $\begin{array}{l}\text { Type of } \\
\text { treatment }\end{array}$ & $\begin{array}{c}P\left(V_{\alpha=1}\right. \\
)\end{array}$ & $\begin{array}{c}\text { Relative } \\
\text { difference, } \\
\delta \% \\
\end{array}$ & $P(V)_{a v}$ & $\alpha_{a v}$ \\
\hline 1 & $\begin{array}{l}\text { Boring, } \\
\text { rough } \\
\text { honing }\end{array}$ & 0,31096 & $\delta_{1,2}^{a}=33,6$ & 0,5951 & 0,445 \\
\hline $2 a$ & $\begin{array}{l}\text { Rough } \\
\text { honing }\end{array}$ & 0,4681 & $\begin{array}{c}\delta_{a, b}=33,9 \\
7\end{array}$ & 0,7215 & 0,47 \\
\hline $2 b$ & Fine honing & 0,7089 & $\delta_{1,2}^{b}=56,13$ & 0,9265 & 0,68 \\
\hline За & $\begin{array}{c}\text { Grinding - } \\
\text { neck, Salnik }\end{array}$ & 0,5084 & $\delta_{a, b}=5,11$ & 0,7865 & 0,50 \\
\hline $3 b$ & $\begin{array}{c}\text { Grinding - } \\
\text { neck, Flange }\end{array}$ & 0,5358 & $\delta_{b, c}=1,51$ & 0,7969 & 0,52 \\
\hline 3c & $\begin{array}{c}\text { Grinding - } \\
\text { neck, Main } \\
1\end{array}$ & 0,5440 & $\delta_{a, c}=6,54$ & 0,7700 & 0,77 \\
\hline $4 a$ & $\begin{array}{l}\text { Grinding - } \\
\text { neck, Pin } 1\end{array}$ & 0,5172 & $\delta_{a, b}=4,93$ & 0,7638 & 0,50 \\
\hline $4 \mathrm{~b}$ & $\begin{array}{l}\text { Grinding - } \\
\text { neck, Main } 1 \\
\text { (according } \\
\text { to ISO } \\
13505 \text { ) } \\
\end{array}$ & 0,7677 & $\delta_{3,4}^{b}=30,21$ & 0,870 & 0,77 \\
\hline $5 a$ & $\begin{array}{l}\text { Wide } \\
\text { burnishing, } \\
\text { Salnik }\end{array}$ & 0,5146 & $\begin{array}{c}\delta_{a, b}=10,2 \\
9\end{array}$ & 0,7688 & 0,52 \\
\hline $5 b$ & $\begin{array}{c}\text { Wide } \\
\text { burnishing, } \\
\text { Flange }\end{array}$ & 0,5736 & $\delta_{4,5}^{a}=0,34$ & 0,8117 & 0,55 \\
\hline $6 a$ & $\begin{array}{l}\text { Polishing, } \\
\text { Main } 4\end{array}$ & 0,6889 & $\delta_{a, b}=4,53$ & 0,9205 & 0,67 \\
\hline $6 b$ & $\begin{array}{l}\text { Polishing, } \\
\text { Pin } 2\end{array}$ & 0,7216 & $\delta_{5,6}^{b}=20,51$ & 0,9250 & 0,68 \\
\hline
\end{tabular}

Similar characteristics were obtained for various methods of surface treatment. They are consolidated in the table 4 .

Table 4. Results of computational and graphic studies of surface texture probabilistic parameters for different processing types.

Thus, the probabilistic characteristics of filling a rough layer with a material give integral assessment of the part surface texture, taking account of the geometry, 
shape, frequency and height of the layer peaks and valleys represented by the profilogram.

The results of computational and graphic studies of the influence of the part surface treatment methods on the probabilistic characteristics of the rough layer filling shows that their relative difference varies from $0.34 \%$ to $56.13 \%$. This range makes it possible to quantitatively evaluate the compliance of the surface texture with quality standards with a sufficiently high accuracy using proposed probabilistic characteristics.

\section{Conclusions}

This work leads us to the following conclusions:

1. The probability of filling the rough surface layer with a material derived from profilogram analisys is proposed to assess the surface texture.

2. Analytical dependences are obtained for calculating the probability of filling the rough layer with a material along layer sections, and the probability of the through-thickness filling.

3. An example is introduced of a computationalgraphic analysis of process-induced surface defects.

4. Probabilistic characteristics of surfaces obtained from various processing types are presented.

\section{Acknowledgements}

This research was funded by the grant of Russian Science Foundation (project NO 19-19-00171).

\section{References}

1. Geometrical Product Specifications, ISO 4287, (1997)

2. Geometrical Product Specifications, ISO 4288 (1996)

3. R. Deltomber, K.J. Kubiak, M. Bigerelle, Scanning, 36(1), 150-160 (2014) http://dx.doi.org/10.1002/sca.21113

4. P.F. Zibrov, O.G. Zibrova, Bulletin of the Volga University named after V.N. Tatishchev (Translated from russian), 2(3), 32-36 (2015) [in Russia]

5. S.N. Grigoriev, G.M. Martinov, Procedia CIRP, 46, 525-528 (2016)

DOI: 10.1016/J.PROCIR.2016.04.036

6. S.N. Grigoriev, D.A. Masterenko, V.I. Teleshevskii, P.N. Emelyanov, Measurement Techniques, 55(11), 1311-1315 (2013)

7. S.N. Grigoriev, G.M. Martinov, Procedia CIRP, 1(1), 238-243 (2012)

8. M.A. Volosova, S.N. Grigor'ev, V.V. Kuzin, Refract Ind Ceram., 56, 91-96 (2015)

9. V.V. Kuzin, S.N. Grigor'ev, M.A. Volosova, Refract. Ind. Ceram., 54, 376-380 (2014)

10. M.A. Volosova, S.N. Grigor'ev, V.V. Kuzin, Refract. Ind. Ceram., 55, 565 (2015)
11. A.S. Metel, V.P. Bolbukov, M.A. Volosova, S.N. Grigoriev, Yu.A. Melnik, Instrum, Exp. Tech., 57(3), 345 (2014) 